\title{
ASSESSING DISASTER RISK AND RESILIENCE: A CASE STUDY IN URBAN FLOOD VULNERABLE COMMUNITY IN KAMPUNG ASAHAN, KUALA SELANGOR
}

\author{
M. F. Sardi ${ }^{1,2 *}$, K. A. Razak ${ }^{1,3}$, R. Zaini Bakri ${ }^{4}$ \\ ${ }^{1}$ Razak Faculty of Technology and Informatics, Universiti Teknologi Malaysia (UTM), Jalan Sultan Yahya Petra, 54100, \\ Kuala Lumpur, Malaysia - mohamadfazlisardi@graduate.utm.my, khamarrul.kl@utm.my, \\ ${ }^{2}$ Malaysia Civil Defence Force, Prime Minister's Department, Jalan Padang Tembak, 50556 Kuala Lumpur, Malaysia - \\ fazli@civildefence.gov.my \\ ${ }^{3}$ Disaster Preparedness and Prevention Center, Malaysia-Japan International Institute of Technology (MJIIT), Universiti Teknologi \\ Malaysia (UTM), Jalan Sultan Yahya Petra, 54100, Kuala Lumpur, Malaysia \\ ${ }^{4}$ OUM Business School, Open University Malaysia - rosdianazainibakri93@ gmail.com
}

KEY WORDS: Urban Flood, Disaster Risk Reduction, Disaster Preparedness, Community Resilience

\begin{abstract}
:
The urbanization rate in Malaysia is predicted up to $85 \%$ in 2040 with a population reaching up to 46 million. Given urban development pressure, extreme climate and environmental degradation, the number of disasters is increasing with a large number of victims, casualties, and damaged infrastructures. Therefore, there is a critical need to quantify the underlying risks, strengthen disaster preparedness and build a resilient urban community in a disaster vulnerable region. This study aims to provide a new insight into the assessment of urban resilience and the development of social resilience strategy for reducing disaster risk in Malaysia. A study area is located in Kampung Asahan, Kuala Selangor district, the second biggest district in the state of Selangor. It is worth to mention that Selangor is the most economically vibrant state that contributes to 23\% to the national Gross Domestic Products (GDP) with a population of 6.38 million residents. This study analyses a series of historical floods, the potential for future occurrence and socio-economic impact for supporting risk-informed development and investment. A questionnaire survey was organized to establish the baseline data, analysed local risk profiles while preparing an action plan and flood preparedness toolkit towards strengthening urban resilience in Selangor. This study is in line with the spirits underlying the Sendai Framework for Disaster Risk Reduction 2015-2030, Urban Agenda 2030 and supporting the use of science, technology and innovation for disaster risk reduction (DRR), mainstreaming DRR into future development planning, and making our cities more resilient to future disasters in Malaysia.
\end{abstract}

\section{INTRODUCTION}

Flooding is the most frequent global phenomena that happen with little warning. Floods are affecting urban areas more frequently due to unplanned development and insufficient flood management strategy. The urban area can be defined as an area with "large settlements, high population densities that conduct non-agricultural activities with high mobility". Mitigating urban flooding is costly and difficult to manage. Lack of ability to utilise resources has been causing the community to experience the negative after effect of the disaster. Community with high capacity and low vulnerability will be able to survive when disaster strikes. Capacity can be defined as the availability of resources and skills also capability to prepare before the disaster, response during a disaster and recover after a disaster (UNISDR, 2017).

Most developing countries have high vulnerability and lack of disaster preparedness planning, as their focus is on the developing the country especially infrastructure development. Disaster event had caused an increasing number of poverty especially in a less developed country (CRED, 2018). It is important for all the relevant stakeholders to take necessary actions to overcome disaster risk and provide a more resilient and safe place for future generations. It is fundamental for the vulnerable community to have a thorough understanding of urban flood hazard and its associated risk. Yet the knowledge and information still remain implicit among the community members. Sharing of information and knowledge is vital to sustain the community livelihood. The vulnerable community needs to know what to do, where to go, and how to protect themselves. Natural hazard affects community well-being and livelihood, infrastructures and properties especially in the developing countries which consequently affect the ability to achieve sustainable development and reduce poverty. The effect of a natural disaster can be reduced by strengthening public awareness and knowledge on disaster preparedness. Enhancing the coping capacity of the community is one of the effective methods to manage and reduce disaster risks.

The government, local authorities, non-profit organisations and the community should work together before, during and after the disaster. Members of the affected community should cooperate and engage with the disaster risk reduction effort instead of perceiving themselves as a victim. A community that is able to adapt and cope with changes resulted from the disaster also return to norms efficiently and rapidly will be able to sustain during any disruptive event. Community resilience can be developed through the relationship among the people in the community, infrastructure and economic activities that the community depends on. This is because the community capitals and sense of togetherness will help the community to survive and fulfil their needs both during normal and crisis time. Previous research suggested that enforcement of the local law, allocation of sufficient funding, and holistic implementation of disaster risk reduction measures in planning and development, also comprehensive engagement with related stakeholders will enhance resilience building in Asia and the Pacific (Lim, 2015). Authorities in Malaysia have been made continuous effort to improve the disaster management system of the country through 
the establishment of National Security Council Directive No.20, enforcement of law and regulation, public awareness and education, development of forecasting and warning system, build-up of mitigation structure, skills transfer from various countries and background (Mat Said et al., 2011).

This study is in compliance with the priorities in action of the Sendai Framework for Disaster Risk Reduction 2015-2030 that emphasize the need to enhance the level of understanding disaster risk and improve disaster preparedness. The Sendai Framework highlighted that the community plays a vital role in reducing risk, preventing new risk, enhancing preparedness level and strengthening their own resilience. Economic losses, loss of lives and future damage can be reduced once the community is empowered with the necessary skills and knowledge about disaster risk reduction. The community is considered as resilient to disaster when they are capable to survive and able to build back better after the disaster.

Therefore, this study focuses on assessing both underlying and associated risk of urban flood in the study area in order to enhance the resilience of the vulnerable community. The community resilience was assessed using Torrens Community Disaster Resilience Scorecard that emphasized on the following components; (1) connectedness, (2) risk and vulnerability, (3) procedures that support community disaster planning, response and recovery and (4) available resource in the community that support disaster planning, response and recovery (Arbon P. et al., 2012). The result of this study can be used to assess and determine necessary actions to be taken in order to create a resilient community towards disaster especially flood. A resilient and well-prepared community will be able to cope and self-care during disaster.

\section{DISASTER RESILIENCE}

\subsection{Disaster Resilient Community}

Holling (1973) defined the resilient term in ecology as 'a measure of the persistence of systems and of their ability to absorb change and disturbance and still maintain the same relationship between population and state variable'. Over the time, and after intensive continuous research have been carried out on the subject, resilient has been defined as a comprehensive way to include 'the involvement of the development of the ability or capacity and build back better aftermath'. Furthermore, common attempts to define the term resilience community evolving cross research areas and expressing different meaning based on the field of interest.

From the above review of literature on community resilience definition, it can be concluded that the definitions of resilience community are constructed based on the capacity, ability, capital, temporal and level of achievement. It refers to the strength that community possesses in terms of resources or capital either it is inherent or developed over time to a better readiness in facing disturbances. A community with a strong capitals from their three (3) main components which is economic capital, social capital and environmental capital (Wilson, 2011)presumably showing stronger resilience spirit and will be able to build back better when a disturbance occurs. A community towards disaster will be able to recover in much shorter time due to lower damage level and vice versa. Therefore, it become necessary for building resilience community right from the individual level and community level.
United Nation International Strategy for Disaster Reduction (UNISDR, 2007) also recognised that local community capacity provide fundamental inputs in DRR and it is important to focus on how to strengthen their capacity in order to build a strong resilience community. Resilience community independence are based on the ability of this community organization to cope with the disaster and continue their livelihood aftermath. Their potential outcomes aftermath can be stated as follows: (i) better recovering and returning - 'build back better'; (ii) merely recover and return as normal life; (iii) recoverable, but rather worse than ever; and (iv) cannot be fully recovered or collapse.

The importance of capacity development in Disaster Risk Management (DRM) for building disaster resilience is certainly appropriate. It is a way forward, positive and definite steps towards achieving a prepared, equipped and resilient city and community. Disaster impacts may be reduced through improved social and organizational factors such as increased wealth, the widespread provision of disaster insurance, the improvement of social networks, increased community engagement and participation, and the local understanding of risk (Cutter et al., 2008), as well as through improvements in resilience within natural systems.

In event of natural disaster in Malaysia, communities need to strengthen their disaster resilience through better communication, cross-community cooperation, maximizing opportunities to compare their plans, actions and reaction with those reported in research publications, and aligning their community disaster management with reported best practice internationally while acknowledging the need to adapt such practice to local contexts (Salizar Mohamed Ludin, 2016). In this light, this research is formulated based on understanding that changes in environment is inevitable, and has affected livelihood of many people and their community despite many obstacles and challenges, there are some community are able to persist and be resilient in dealing with disasters and uncertainties.

\subsection{Study Area}

The study area is located in Kampung Asahan, Mukim Pasangan, Kuala Selangor with sparse residential density surrounded by oil palm plantations (Figure 1). A total area is about 1 hectare and consisting of 1,120 populations approximately, which mainly made up by Malay (Field survey, 2018). The study area is situated about 10.5 kilometre from the Kuala Selangor town and 67.0 kilometre from the Kuala Lumpur. It is about 11 kilometre from the nearest coastline and located 200 metre from the trunk of Sungai Selangor and 13 kilometre from its river mouth (Selangor Disaster Management Unit, 2019). The research was conducted in Kampung Asahan, Kuala Selangor specifically with the communities in Batu 7, Batu 8, Lorong Cempedak, Lorong Tebu and Lorong Pisang. The Kampung Kuantan Fireflies Park (Kelip- kelip Kampung Kuantan) is one of major attractions in Kuala Selangor. Rapid urbanisation in the vicinity area, bad practice of waste management and poor drainage system had caused an overflow of riverbank to the low lying areas during heavy rainfall. Kampung Asahan had recorded some historical flood events, recently they received two (2) major flood occurrences in 2018 (Table 1). 


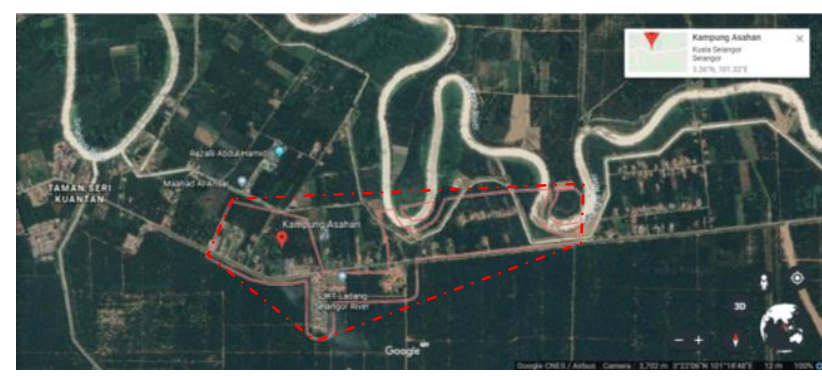

Figure 1. Location of the Study Area in Kampung Asahan, Kuala Selangor (see red polygon)

\begin{tabular}{|c|c|}
\hline $\begin{array}{c}\text { Date of Flash Flood } \\
\text { Occurred }\end{array}$ & $\begin{array}{c}\text { The Opening of Temporary } \\
\text { Evacuation Centre }\end{array}$ \\
\hline 5 to 22 Dec 2018 & $\begin{array}{c}\text { Yes (Sekolah Kebangsaan } \\
\text { Pasangan) 65 families displaced }\end{array}$ \\
\hline 5 November 2018 & None \\
\hline 24 May 2018 & $\begin{array}{c}\text { Yes (Sekolah Kebangsaan } \\
\text { Pasangan) 23 families displaced }\end{array}$ \\
\hline 24 January 2018 & None \\
\hline
\end{tabular}

Kuala Selangor in 2018 (Selangor Disaster Management Unit, 2018)

The flood occurrence in Kampung Asahan caused by three (3) events that happened concurrently: high sea tides downstream; high river flow of Sungai Selangor from upstream; and heavy rainfall within the local basin (Selangor Disaster Management Unit, 2019). The community stated that the flood occurrence had caused interruption to their social activities also disrupt transportation and external relations. Furthermore, the vulnerable community stated that heavy rainfall, construction of houses in low-lying areas and poor drainage system were the reasons that caused flooding in the area (Field survey, 2018). Most of the houses in the area were built on the ground level. The communities aware of the construction of the houses on tall pillars with the floor level at about 1.5 to 2 meter above the ground to prevent their houses from flood (Field survey, 2018).

\subsection{Torrens Community Resilience Scorecard}

A community has the ability to manage social, economic and environmental capital will achieve resilience. Adaptation to the worst scenario, take initiative to cope and develop a better surrounding through past experience is part of the characteristics of a resilient community. Torrens Community Resilience Toolkit also assessed community resilience through four (4) main components: community connectedness; risk and vulnerability; planning and procedures; and available resources to support disaster planning, response and recovery. The scorecard was community friendly, and easy to understand by multiple ranges of community members. Four (4) components of Torrens Community Resilience Scorecard (Arbon P. et al., 2012) are explained:-

\section{a) community connectedness}

The component discussed the degree of connectedness among the community members and other related stakeholders also availability and functionality of communication channel across the community members especially related to disaster management initiative.

b) community risk and vulnerability
The component assessed awareness and knowledge of the community about the potential hazard. The community also needs to have a basic understanding of the community members as a whole such as the existence of vulnerable group such as elderly, disable people, bed-ridden patient. In addition, this component also highlighted the road infrastructure facility. This is because road infrastructure has a high tendency to fail when disaster occur which will increase the vulnerability of the community and cause difficulty for external aid to reach the area.

c) procedures or action to support community disaster planning, response and recovery

This component required the community to evaluate the degree of measures taken by the members to enhance disaster preparedness and resilience.

d) availability of resources within the community groups A brief assessment on the skills, facilities, resources and knowledge of the community to be utilized in disaster planning, response and recovery.

\section{METHODOLOGY}

The quantitative approach was conducted by using the Torrens Community Resilience Toolkit. The analysis of the scorecard provides a score of the community resilience in Kampung Asahan, Kuala Selangor. The toolkit was used by the Malaysian Medical Relief Society (MERCY Malaysia) to assess the community resilience in Kuala Krai, Kelantan; Karo, North Sumatera; Berastagi, North Sumatera; Leyte, Philippines; Kuala Krau, Pahang; Lanchang, Pahang; Johor Bharu and Aceh, Indonesia (MercyMalaysia, 2018).

The interview session with the Chief Assistant Secretary of Selangor Disaster Management Unit was done to validate the propose action plan and flood preparedness toolkit. A participatory-based method was used to collect a detailed information and determine the causal factors contributing to the disaster. The random sampling was used with the questionnaire survey involving 100 respondents.

47 respondents are male while the other (39) are female, with the age between 15 and 69 years old. $45 \%$ respondents had lived in Kampung Asahan more than forty years. 80\% respondents had experienced flood in the past, while the remaining did not have previous experience with flood event mainly by the reasons, e.g. staying in other area due to working or pursuing his studies or just stayed in Kampung Asahan less than one year. Most of the communities agreed that prolonged and heavy rainfall, low-lying area and overflow of river water were the reasons that causes flooding in Kampung Asahan. The community was badly affected with the disruption of daily activity, e.g. the children cannot go to school and also disruption of business operation in the area. Luckily the flood took place during the school holiday, and the school building can be used as a temporary evacuation centre.

The questionnaires were distributed at Sekolah Kebangsaan Pasangan, the temporary flood evacuation centre. The questionnaire survey provided range of information about the community members including background details of the respondent, level of connectedness among the community members, level of risk and vulnerability in the community, 
procedures to support community disaster planning, and also available resources for emergency planning, response and recovery in the community.

Meanwhile, the interview session was carried out at the end of the study in order to validate the finding of the study. Selangor Disaster Management Unit (SDMU) was responsible to manage various disaster in the state. Engagement with the government agencies provide some baseline information for developing resilient community. Therefore, it is an important step to gather inputs from the experts for developing a community-based action plan.

Numerical data from the survey was used to summarize the findings that represent the community as a whole. Data from the survey had answered the following research question:

i. What is the level of community resilience in terms of connectedness; risk and vulnerability; procedures and resources that support community disaster planning, response and recovery?

ii. How connected are the members of the community in the study area?

iii. What is the level of risk and vulnerability of the community in the study area?

iv. What are procedures that support community disaster planning, response and recovery in the study area?

v. Availability of resources within the community in the study area for emergency planning, response and recovery?

The questionnaire consists of 41 questions that divided into five divisions:- background detail; connectedness of the community members; level of risk and vulnerability in the community; procedures to support community disaster planning, response and recovery; available resource to support community disaster planning, response and recovery. Torrens Community Disaster Resilience Scorecard was revised and adapted to local context. The wording of the scorecard has been reviewed and revised to ensure that the score is easy to understand by the community. Moreover, the scorecard provides insight into understanding a risk profile, designing action plans for resilience. The result of the scorecard can act as a guideline to promote disaster preparedness and resilience to the community. The Likert scale ranging from 1 (low resilient, in the red zone) to 5 (very resilient, in the green zone). The score of community resilience was obtained by calculating the sum of all the scores based on the equation (1):

Community Resilience $=(a+b+c+d) / 145 \times 100 \%$

Where,

$\mathrm{a}=$ community connectedness score (30 marks maximum)

$\mathrm{b}=$ risk and vulnerability score (40 marks maximum)

$\mathrm{c}=$ procedures or action to support community disaster planning, response and recovery score (25 marks maximum)

$\mathrm{d}=$ resources to support community disaster planning, response and recovery score (50 marks maximum)

The average of the total scores was obtained from the completed scorecard to represent the community in Kampung Asahan, Kuala Selangor. The use of the scorecard will help to identify the degree to which the community are able to build their resilience. It also highlights local risk and importance of community engagement and collective responsibility to overcome the impact of the unexpected event.

\section{FINDINGS AND ANALYSIS}

The overall score was 145 with score components represented 30 (connectedness), 40 (risk and vulnerability), 25 (procedures) and 50 (resources). Table 2 shows the classification of scores for all the four components that were assessed in the Torrens Community Disaster Resilient Scorecard.

\begin{tabular}{|c|c|c|c|}
\hline Components & Red Zone & Caution Zone & Going Well \\
\hline Overall Score & $25 \%$ & $26 \%-75 \%$ & $76 \%-100 \%$ \\
& $(29-36)$ & $(37-109)$ & $(110-145)$ \\
\hline Connectedness & $25 \%$ & $26 \%-75 \%$ & $76 \%-100 \%$ \\
& $(6-7)$ & $(8-22)$ & $(23-30)$ \\
\hline Risk / & $25 \%$ & $26 \%-75 \%$ & $76 \%-100 \%$ \\
Vulnerability & $(8-10)$ & $(11-30)$ & $(31-40)$ \\
\hline Procedures & $25 \%$ & $26 \%-75 \%$ & $76 \%-100 \%$ \\
& $(5-6)$ & $(7-18)$ & $(19-25)$ \\
\hline Resources & $25 \%($ & $26 \%-75 \%$ & $76 \%-100 \%$ \\
& $10-12)$ & $(13-37)$ & $(38-50)$ \\
\hline
\end{tabular}

Table 2. Classification of scores for the Torrens Community Disaster Resilience Scorecard

\subsection{Connectedness}

The results are presented based on the list of questions and outcomes from the interviews sessions with the local leaders, local communities, and stakeholders. This study provides an overview of Torrens Scorecard output, which shows the scores, proportion and trends. Half of the total respondents agreed that the whole community collaborate actively throughout the disaster management cycle including disaster preparedness, during disaster and recovery phase. Likewise, the other $38 \%$ felt that the community collaborated while the other $9 \%$ believed that the community members involved actively in the annual planning activity related to disaster management cycle.

Overall, the average score of connectedness among the community members was $20(67 \%)$. The average score obtained from the 86 completed questionnaires filled up by the community members. The community in Kampung Asahan was in the caution zone in terms of connectedness components of the community resilience towards urban flood.

\subsection{Risk and Vulnerability}

64 out of 86 respondents agreed that less than $5 \%$ of the population were considered as vulnerable and need special attention as shown in Table $2.8 \%$ of the respondents felt that $10 \%$ of the population were considered as vulnerable such as pregnant women, children, elderly and disabled person while the other $8 \%$ rated that none of the population was vulnerable. The other $6 \%$ agreed that $15 \%$ of the populations in Kampung Asahan were vulnerable. The remaining $4 \%$ felt that more than $20 \%$ of the population in the study area can be considered as vulnerable community. Overall, the average score regarding the level of risk and vulnerability in the community of Kampung Asahan was 26 out of 40 , about $65 \%$. The average score obtained from the 86 completed questionnaire filled up by the community members. Level of risk and vulnerability in the community of Kampung Asahan was classified in the caution zone. The level of risk and vulnerability in the community was part of the components used to assess the community resilience towards urban flood. 


\subsection{Procedures}

Data obtained from the 86 completed questionnaire resulted in an average score of 14 out of $25(56 \%)$ in terms of procedures or actions to support disaster planning, response and recovery. It was categorised as the caution zone. Data showed that there were only limited actions taken by the community in Kampung Asahan to support disaster planning, response and recovery which affecting the urban community.

\subsection{Resources}

The average score of resources component obtained by the community was 30 out of $50(60 \%)$. The community was in the caution zone in terms of availability of resources in the community that can be used and optimised for disaster planning, response and recovery.

All in all, the community of Kampung Asahan were categorised in caution zone in terms of community resilience towards urban flood. The overall score obtained by the community was 90 out of $145(62 \%)$. It can be concluded that the level of community resilience towards urban flood was still moderate and need a lot of improvements in order to become a resilient community.

Analysis of the data from the questionnaire survey concluded that the community in Kampung Asahan were categorized in the caution zone in terms of community resilience (Table 3 ). The community were categorized in the same zone for all four components assessed in the Torrens Community Disaster Resilience Scorecard.

\begin{tabular}{|l|c|}
\hline Zone & CAUTION!!! \\
\hline Overall Score & $62 \%(90$ out of 145$)$ \\
\hline Connectedness & $67 \%(20$ out of 30$)$ \\
\hline Risk / Vulnerability & $65 \%(26$ out of 40$)$ \\
\hline Procedure & $56 \%(14$ out of 25$)$ \\
\hline Resources & $60 \%(30$ out of 50$)$ \\
\hline
\end{tabular}

Table 3. Score obtained by the community in Torrens Community Disaster Resilience Scorecard

In terms of the connectedness component, the community felt that they only have limited access to a range of communication methods to gather and share information during times of emergency. The community depends on the information disseminated about the potential flooding event by the head of village through media social applications. It is important to note that the usage of social media applications may be limited to the community with the age group between 60 years old and above. This group were the one who stayed on their own at home during working hours and posed high vulnerability due to limited physical ability and impaired sensory abilities. In addition, there was a high probability that the telecommunication services can be interrupted during massive flooding. Thus, the community should develop a communication plan that is suitable with all age groups and resistance from damages.

It is important to increase the awareness of the community in Malaysia about the existence of "Portal Bencana" website and "Agensi Pengurusan Bencana, Jabatan Perdana Menteri" Facebook page since both of the medium provide information for the public about the potential and on-going disaster event in Malaysia. Active collaboration across the community in disaster preparedness, during disaster and disaster recovery, was a plus point for the community in Kampung Asahan. This kind of culture will promote a sense of togetherness and cooperation among the community members. The community members were helping each other during the evacuation process on the recent flood occurrence in December 2018.

Assessment of the risk and vulnerability had placed the community in the caution zone. The community were exposed to several risks due to limited exposure to important information. The community focused on single risk which was a flood and not aware of the existing flood hazard map developed by the Department of Irrigation and Drainage. The map showed that Kampung Asahan has the potential to experience flooding with more than 1.2-metre depth. Figure 2 shows the aerial view of flood occurred at Kampung Asahan on December 12, 2018 (SDMU, 2018).

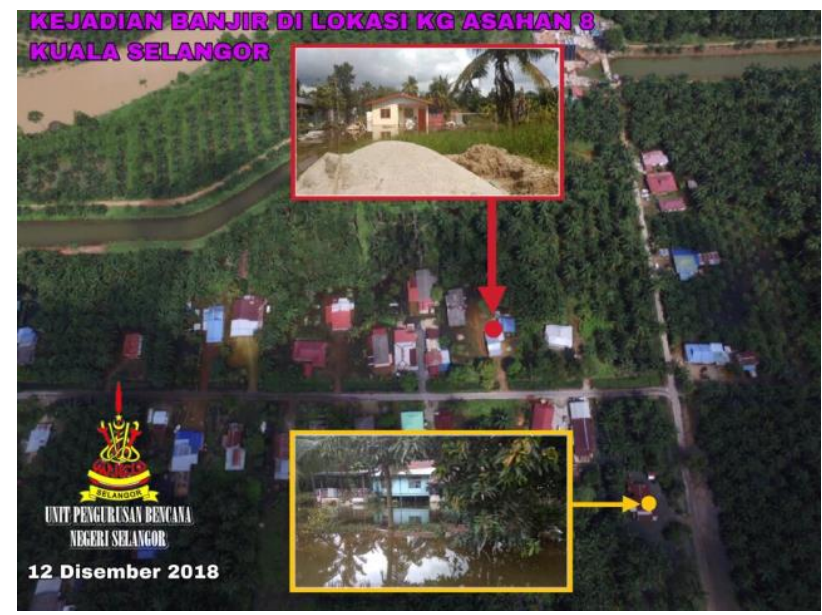

Figure 2. The Aerial View of Flood Occurred at Kampung Asahan on December 12, 2018 (Selangor Disaster Management Unit, 2018)

Authorities should determine the reason why the community in the area were not aware of the existence of the map even after seven years of being produced. This condition showed that the community did not get access to the important information and aware of the exposure to the potential flood risk. The community still need to be informed about the potential of flood event even precaution measures had been taken by the Department of Irrigation and Drainage (DID) through the installation of water pump. Lack of active involvement and collaboration in disaster response and recovery will increase the vulnerability of the community in Kampung Asahan. Their potential capacity was not utilised that makes them perceived themselves as the aid recipient instead of acting as the first responder when disaster strikes. The transient population are often neglected in the planning for disaster response and recovery. Community participation and engagement in disaster management can become a good platform for the community to share ideas and opinions also take actions in issues that affecting their daily lives.

Road infrastructures around the Kampung Asahan were only accessible and convenience during normal time but limited during the disaster. Only the main road was accessible to the road users during the flood. 


\section{DISCUSSION}

Urban flood is one of the disasters that affects the population livelihood on regular basis globally. Our country was one of the victims of the urban flood. The urban flood happened due to natural process and human activities. As for the community in Kampung Asahan, they agreed that urban flood was caused by long and heavy rainfall, low-lying area and poor drainage system. Moreover, some community members emphasized on the incomplete water pump project in the study area as one of the reasons for urban flood occurrence.

Community resilience towards urban flood can be considered as moderate. The findings were later distributed to the community in the study area. The community gained moderate scores for all the four elements (connectedness of the community members; the level of risk and vulnerability; procedures to support disaster planning, response and recovery; available resources to support disaster planning, response and recovery) that were assessed in the Torrens Disaster Resilience Scorecard.

A simple, easy-to-execute strategy and plan was proposed in order to enhance community resilience towards urban flood. Further discussion about the strategy and plan is available in the next section. A toolkit on what to do before, during, and after the flood was disseminated to the community in Kampung Asahan, and also referred as a guideline.

The community felt that between $61-80 \%$ of the total populations have the capacity to move to safety independently. The independent capacity of the community in Kampung Asahan resulted in a smooth evacuation process in times of emergency. The community in Kampung Asahan relied on their previous and grassroots experience in response to urban flooding that happens in their community. Since the community had experienced flooding every year, the community already knew what should be done when the flood happened. When the head village allowed the opening of a temporary flood evacuation centre, head of household will evacuate women and children to the temporary evacuation centre on their own. Besides that, less than $5 \%$ of the population were considered as vulnerable and need special attention like elderly, disabled people. Most of the elderly stayed with their children (Field Survey, 2018).

On the other hand, the community should start taking actions and make efforts in enhancing disaster planning, response and recovery. There was no guideline that worked as a reference for the community members in relation to disaster management. Nowadays, knowledge and information on how other communities cope and overcome urban flooding were available widely online and offline. Community committee especially Majlis Pengurusan Komuniti Kampung (MPKK) can take initiative by assessing lesson learned by other communities at the local and international levels. Education was one of the channels to enhance the culture of resilience in a community. Previous research agreed that community education help enhance community preparedness towards disaster (Mat Said et al., 2011). The community were ready and able to respond and recover instantly when they had sufficient knowledge and preparation for the disaster.

As for the community in Malaysia, the MPKK was responsible to take care of the community on their own for the first 24 hours. According to the Directive No. 20, after 24 hours it was the role of the Social Welfare Department to manage the evacuation centre, distribute aid to the victim and register the disaster victim for rehabilitation purpose. Men of the house will stay to take care of the house and property and start cleaning the house when the water level decreasing. Most of the time only the furnitures were damaged while the house structures were still intact. It can be concluded that the community was equipped with the knowledge of flood response but still lack of flood preparedness training and knowledge. Thus, a comprehensive guideline for disaster management should be established by the local government as part of the effort to support the development of a disaster resilient community.

Moreover, the community in the study area agreed that there were no planned activities done by the government or the community members on all-hazard resilience. National Disaster Management Agency (NADMA) with the support of Malaysia Civil Defence Force (MCDF) as the Disaster Management Secretariat at national level, state level and district level should widespread their effort in conducting a disaster awareness and preparedness programme at the community level like "Tsunami Evacuation Exercise in Kota Kuala Muda, Kedah" the that had been conducted recently. This kind of programme should reach all the vulnerable community in Malaysia.

The community committee was restricted to conduct this kind of programme on their own due to the lack of technical skills and knowledge. It is important to emphasize that the community did not implement disaster preparedness activities in their daily lives. Actions were taken when necessary even the community were informed about the importance of disaster preparedness routinely. The community in Kampung Asahan took less attention to disaster preparedness action since previous flood event only about $0.3 \mathrm{~m}$ up until $0.6 \mathrm{~m}$ water depth level (Fieldwork survey, 2018). Thus, the community perceived flood as not dangerous. This kind of attitude is in line with the previous studies that the perception of the community towards the previous flooding experience was the cause of their current flood preparedness initiatives (Soetanto et al., 2017).

10 elements were considered in assessing the available resources in the community of Kampung Asahan that can be used in disaster planning, response and recovery. The community felt that only some local sources were involved in disaster management with a range of $41 \%$ until $60 \%$ of them possessed useful skills. Some examples of useful skills and knowledge that can be utilised in disaster management at the community level are first aid, knowledge of the evacuation route, knowledge and awareness about the abnormal river water level, personal hygiene skills and communication skills. In addition, the community agreed that the available health facilities were functioning well.

Only 1 out of 86 respondents among the community in Kampung Asahan felt most schools actively participated in disaster preparedness education at the community level. This data supported the report published by the Department of Statistics Malaysia (2018) that Malaysia needs to take action and make an effort in integrating awareness raising, adaptation and impact reduction into the primary, secondary and tertiary curricula. Besides that, the study found that the community in the study area has the ability to coordinate and cooperate in making a decision before, during and after a disaster but they were still dependent with the aid of agencies. This statement was proven since the community only prepared two days' supply of food and clean water as a preparedness measure in case of disaster since they believed that aid will be given and 
provided by the government agencies. It is important to provide training to the community members in relation to disaster management skills to develop a resilient community that not depend on governmental aid. Education can help the community to prepare, respond and recover from disaster instantly. Both formal and informal learning activities that help to enhance community resilience towards urban flooding can be considered as a community education process. A well-equipped community with the necessary knowledge and skills will be able to withstand disaster and its consequences. They also learnt from the experience and ability to improve their capabilities and response when the next disastrous event occurs. Public education campaigns, advocacy and awareness raising programs can be done at the community level.

Active collaboration was made between the community in Kampung Asahan and the community in Kampung Kuantan. A few volunteers from the neighbouring village came to assist at the evacuation centre during the recent flood event (Fieldwork survey, 2018). Early warning system referred by the community members were their own initiatives to check and assess the condition of the area. Head of the village and the community members will stay alert during heavy rainfall to assess the water level in the area. If the condition gets worse, the Temporary Evacuation Centre located $1.9 \mathrm{~km}$ from the area will be opened.

\section{Action-oriented Strategy to Strengthen Community Resilience}

A comprehensive and practical action plan was developed to improve community resilience towards disaster. The action plan was developed as a guideline for the community to implement basic and simple measures in developing a safer community. Some measures can be done by the community on their own, while some may need help and guidance from the expertise. A better result can be achieved through the involvement and collaboration of multiple stakeholders. The proposed action plan was designed to enhance the ability of the community to manage the potential flood effectively.

Capacity building and active collaboration are amongst proposed strategies that should be taken by the community in Kampung Asahan as follows:-

a) Capacity building:

First and foremost, it is important to conduct an assessment of the capacity and vulnerability that exist within the community. The community will be able to determine the potential hazard that may impact their community from the assessment. Awareness about the capacity and vulnerability can help to reduce the potential hazard which consequently lower the chances of disaster occurrence. The community will be able to improve their resilience by assessing list of capacities and vulnerabilities of their community. The community should develop training or building capacity activities that will meet the needs of the community members (Macclune et al., 2017; McEwen et al., 2018). Application of the community knowledge in planning necessary measures will result in the effective outcome since the community knew they're surrounding better than others. Sharing of knowledge and skills was one of the methods to enhance community resilience towards disaster. The community will be able to prepare and cope better when they were equipped with the flood management skills and knowledge.
World Meteorological Organization (2017) suggested six steps for community training in flood management as the following, know the situation; identify the local resources; design the training courses; conduct the training; assess the impact of the training, and learn the lessons. Both of the first and second steps was done when community conduct the capacity and vulnerability assessment. Next, the community should design and conduct the training session. It was advisable that the community seek for the collaboration with a governmental agency, nongovernmental organisation and academia to conduct the training. This is in line with the second strategy which emphasises on enhance collaboration.

The community may seek budget from the authorities to conduct the community programme. National Disaster Management Agency (NADMA), Malaysia Civil Defence Force (MCDF), Universiti Teknologi Malaysia (UTM) and MERCY Malaysia are some of the institutions that used to conduct community programme in relation to disaster management. Education and awareness raising are two examples of training that can be done at the community level by using their own resources. The training should engage diverse range of community members. One example of training programme that can be conducted by the community is about the flood evacuation route in Kampung Asahan. All the community members especially housewives, elderly and children should be informed about where to go and which road is accessible during flood event. The campaign, participatory learning, informal education and formal school-based intervention are part of the approaches in enhancing public education and awareness (Cross \& Societies, 2011).

The community will get sufficient information on the exposure of hazard, safe evacuation plan, aware of the vulnerable groups among the community members, and the development of flood preparedness plan. Other than that, the community may propose flood-proofing measures such as placing sandbag. The sandbag can help to lessen the amount of water that enters the house which consequently will reduce the damage to property and furniture. Dry floodproofing is another way that can be adopted by the community in Kampung Asahan by sealing the home exterior with waterproof material like plastics. Relocation and elevated the house structures are two other methods for flood prevention. But, it was not cost-effective and limited in capacity for the up-scaling.

b) Increase collaboration

Collaboration between related stakeholders should be fostered to develop connectivity among the actors. A resilient community can be developed when the related stakeholders played their roles. Kamarudin and Razak (2018) had outlined some strategies to enhance disaster risk reduction at the community level before, during and after the disaster occur. The study showed the importance of collaboration and partnership between government agencies both at the state and federal level, academia, nongovernmental organisation, private sectors and the community itself in building disaster resilient society. Moreover, regular town watching activities should be done with the involvement of the related agencies and the community committee. 
This activity provides a medium for all actors in assessing the condition of the specific area in terms of the disaster mitigation facilities and critical infrastructure such as water pump, sanitation, road infrastructure, drainage system, and safe evacuation zone that are important cycles of disaster management.

\section{SUMMARY AND CONCLUSION}

It is important to note that the concept of community's role and responsibility in the disaster management is relatively new in the country. Thus, a lot of effort and time is required to establish community awareness on their responsibilities. The community in Kampung Asahan did not perceive flood event as vulnerable due to their previous poor flood experience. In addition, SDMU suggested to set up a comprehensive damage assessment method in order to get a better overview on the impact of disaster to the affected community, state government and country. Moreover, the damage assessment will create and enhance the awareness of the related stakeholder on disaster preparedness. The recent fieldwork to the study area concluded that the community in Kampung Asahan were confident with the upgraded pumping system that can solve any flooding in the near future compared other flood mitigation methods. They are also interested to apply the proposed action plan and use the flood preparedness toolkit as a guideline.

\section{ACKNOWLEDGEMENTS}

The authors would like to express sincere gratitude to the MultiHazard and Disaster Risk Laboratory, Razak Faculty of Technology and Informatics, Universiti Teknologi Malaysia (UTM) Kuala Lumpur for the opportunity to be part of the research team in Community-Based Disaster Risk Management (CBDRM Kundang) Focus Group Discussion (FGD) 2018 in Kundang, Selangor. The authors would like to acknowledge Selangor Disaster Management Unit (SDMU), Selangor Civil Defence Force and Mercy Malaysia for their support for this research.

\section{REFERENCES}

Arbon P., Gebbie K., Cusack L., Perera S., \& S.., V. (2012). Developing a Model and the Tools to Measure Community Resilience. Final Report. Torrens Resilience Institute.

CRED. (2018). Natural Disaster 2017 - Executive Summary. Centre for Research on the Epidemiology of Disasters (CRED).

Cross, I. F. o. R., \& Societies, R. C. (2011). Public awareness and public education for disaster risk reduction: a guide: International Federation of Red Cross and Red Crescent Societies.

Cutter, S. L., Barnes, L., Berry, M., Burton, C., Evans, E., Tate, E., \& Webb, J. (2008). A place-based model for understanding community resilience to natural disasters. Global environmental change, 18(4), 598-606.
Holling, C. S. (1973). Resilience and stability of ecological systems. Annual review of ecology and systematics, 4(1), 1-23.

Kamarudin, K. H., \& Razak, K. A. (2018). Comprehensive Study on Community Based Disaster Risk Reduction (CBDRR): The Case of Taman Idaman, Serendah, Hulu Selangor, Selangor,25 May 2017. 41.

Lim, M. B. B. (2015). Building Urban Resilience Through Disaster Risk Reduction in Asia and Pacific. Priorities, Good Practices and Lessons Learnt. Final Report. World Vision International-East Asia.

Macclune, K., Macclune, K., Venkateswaran, K., Allan, C., Jayaraman, M., Odonnell, I., . . . Guibert, G. (2017). Do-ItTogether Toolkit for Building Urban Community Resilience.

Mat Said, A., Ahmadun, F. 1.-R., Mahmud, A. R., \& Abas, F. (2011). Community preparedness for tsunami disaster: a case study. Disaster Prevention and Management: An International Journal, 20(3), 266-280.

McEwen, L., Holmes, A., Quinn, N., \& Cobbing, P. (2018). 'Learning for resilience': Developing community capital through flood action groups in urban flood risk settings with lower social capital. International journal of disaster risk reduction, 27, 329-342.

MercyMalaysia. (2018). 2017 Annual Report: Embracing the Winds of Changes. 161.

Organization, W. M. (2017). Integrated Flood Management Tools Series: Community- based Flood Management.

Salizar Mohamed Ludin, M. A. M., Mohd Khairul Zul Hasyimi Firdaus and Paul Arbon. (2016). Assessment of community disaster resilience among Kelantan flood affected community: a cross sectional study. International Medical Journal Malaysia (IMJM), 15(Supplement Issue), 101-101.

Soetanto, R., Mullins, A., \& Achour, N. (2017). The perceptions of social responsibility for community resilience to flooding: the impact of past experience, age, gender and ethnicity. Natural hazards, 86(3), 1105-1126.

UNISDR. (2007). Building Disaster Resilient Communities: Good Practices and Lessons Learned. A Publication of the 'Global Network of NGOs' for Disaster Risk Reduction 2007. United Nation International Strategy for Disaster Reduction (UNISDR).

UNISDR. (2017). Disaster Resilience Scorecard for Cities. Detailed Level Assessment. United Nations Office for Disaster Risk Reduction.

Wilson, G. (2011). Community Resilience and Environmental Transitions. London: Routledge., 240.

Revised August 2019 